\title{
Lisdexamfetamine Dimesylate: Prodrug Delivery, Amphetamine Exposure and Duration of Efficacy
}

\author{
James C. Ermer ${ }^{1} \cdot$ Michael Pennick $^{2,3} \cdot$ Glen Frick $^{1}$
}

Published online: 28 March 2016

(c) The Author(s) 2016. This article is published with open access at Springerlink.com

\begin{abstract}
Lisdexamfetamine dimesylate (LDX) is a longacting $d$-amphetamine prodrug used to treat attention-deficit/hyperactivity disorder (ADHD) in children, adolescents and adults. LDX is hydrolysed in the blood to yield $d$ amphetamine, and the pharmacokinetic profile of $d$ amphetamine following oral administration of LDX has a lower maximum plasma concentration $\left(C_{\max }\right)$, extended time to $C_{\max }\left(T_{\max }\right)$ and lower inter- and intra-individual variability in exposure compared with the pharmacokinetic profile of an equivalent dose of immediate-release (IR) $d$ amphetamine. The therapeutic action of LDX extends to at least $13 \mathrm{~h}$ post-dose in children and $14 \mathrm{~h}$ post-dose in adults, longer than that reported for any other long-acting formulation. Drug-liking scores for LDX are lower than for an equivalent dose of IR $d$-amphetamine, which may result from the reduced euphorigenic potential associated with its pharmacokinetic profile. These pharmacokinetic and pharmacodynamic characteristics of LDX may be
\end{abstract}

Michael Pennick

mike.pennick@hotmail.com

Shire, Wayne, PA, USA

Shire, Basingstoke, UK

3 University of Dundee, Dundee, UK beneficial in the management of symptoms in children, adolescents and adults with ADHD.

\section{Key Points}

Lisdexamfetamine dimesylate (LDX) is the first, and so far the only, long-acting stimulant in which the active drug is released biochemically in the blood rather than mechanically in the gastrointestinal tract.

The duration of therapeutic action of LDX is longer than that reported for any other long-acting stimulant medication, and extends to at least $13 \mathrm{~h}$ post-dose in children and $14 \mathrm{~h}$ post-dose in adults with ADHD.

The pharmacokinetic and pharmacodynamic characteristics of LDX may be beneficial in the management of symptoms in children, adolescents and adults with ADHD.

\section{Introduction}

The stimulants amphetamine and methylphenidate (MPH) are long-established and effective treatments for attentiondeficit/hyperactivity disorder (ADHD) in children, adolescents and adults [1]. The therapeutic effects of immediaterelease (IR) formulations, however, wear off within 4-6 h, necessitating repeated dosing to achieve symptom control throughout the day [2-5]. To extend the efficacy of stimulants throughout the day and into the evening following a single morning dose, long-acting stimulants have been 
developed [6]. These rely on the gradual and phased release of amphetamine or MPH in the gastrointestinal (GI) tract and, for certain formulations, the duration of action has been reported to extend for up to $12 \mathrm{~h}$ post-dose [7].

Lisdexamfetamine dimesylate (LDX) is the first stimulant prodrug [8], and is approved for the treatment of children, adolescents and adults with ADHD in the USA, Canada, Brazil and Australia. In Europe, it is the only available long-acting amphetamine and is approved in selected countries for the treatment of children and adolescents with a clinically inadequate response to MPH. In Denmark, Sweden and the UK, it is also approved for the treatment of adults with ADHD. LDX has also received approval in the USA for the treatment of moderate to severe binge eating disorder in adults [9].

Unlike other long-acting stimulants, the active drug is not released in the GI tract following oral administration. Instead, the pharmacologically inactive parent molecule, consisting of $d$-amphetamine covalently linked to L-lysine (Fig. 1), is rapidly and actively taken up from the small intestine by carrier-mediated active transport [10], probably via the oligopeptide transporter peptide transporter 1

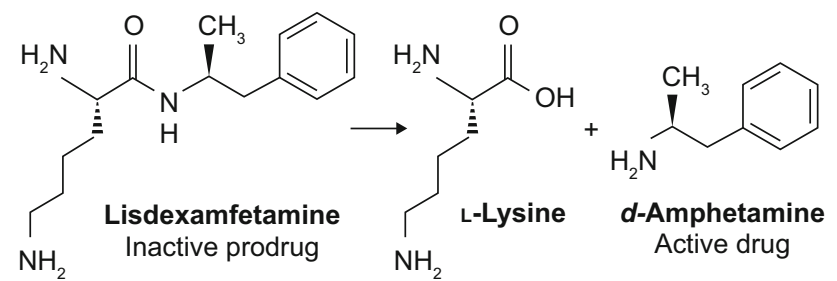

Fig. 1 Chemical structure of LDX and immediate metabolites. In the inactive prodrug LDX, a peptide bond links the amino group of $d$ amphetamine to the carboxyl group of L-lysine. Enzymatic hydrolysis of this bond releases active $d$-amphetamine, and also yields L-lysine as a byproduct. $L D X$ lisdexamfetamine dimesylate
(PEPT1) [11]. Once in the blood, LDX is hydrolysed in erythrocyte cytosol by an unknown aminopeptidase, yielding pharmacologically active $d$-amphetamine (Fig. 2) $[11,12]$. The $d$-amphetamine generated from LDX crosses the blood-brain barrier to access binding sites in the central nervous system [13] and to exert therapeutic effects by increasing noradrenergic and dopaminergic neurotransmission. Here, we discuss the relevance of this distinctive mode of action to clinicians and patients by reviewing the pharmacokinetics and pharmacodynamics of $d$-amphetamine delivered by hydrolysis of LDX. Relevant journal articles and clinical studies were identified by searching PubMed and ClinicalTrials.gov for 'lisdexamfetamine' or 'SPD489'.

\section{Pharmacokinetics of $d$-Amphetamine Delivered by Hydrolysis of Lisdexamfetamine Dimesylate (LDX)}

\subsection{Plasma Concentration-Time Profiles for $d$ - Amphetamine Following Oral LDX Administration}

The pharmacokinetic parameters that describe blood plasma concentration-time profiles and thereby quantify an individual's exposure to LDX or $d$-amphetamine are defined in Table 1.

Figure 3, panels a and b, show the observed blood plasma concentration-time profiles for intact LDX and $d$ amphetamine following oral administration of LDX in children with ADHD $(N=17)$ [14] and healthy adults $(N=11)$ [15], respectively. Tables 2 and 3 summarise published pharmacokinetic parameters for $d$-amphetamine and LDX, respectively, following administration of LDX in
Fig. 2 Systemic delivery of $d$ amphetamine by hydrolysis of LDX in the blood. $L D X$ lisdexamfetamine dimesylate, PEPT1 peptide transporter 1

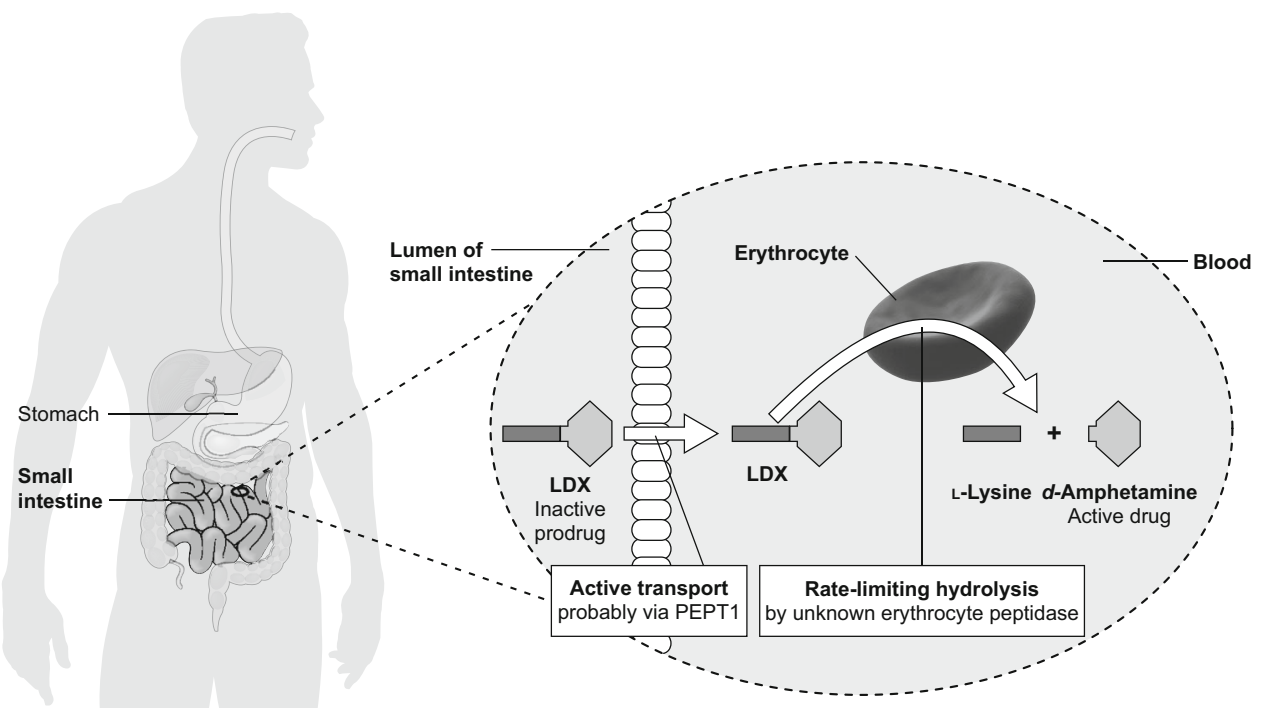


the therapeutic range $(30,50$ or $70 \mathrm{mg} /$ day $)$ to children with ADHD, healthy adults and healthy older adults. The mean time to maximum plasma concentration $\left(T_{\max }\right)$ is longer for $d$-amphetamine $(3.0-4.7 \mathrm{~h})$ than for LDX $(1.0-2.1 \mathrm{~h})$, because of the rate-limited hydrolysis of the parent drug. After peaking, plasma LDX concentrations declined rapidly (mean elimination half-life $\left[t_{1} / 2\right]$, 0.4-0.9 h), whereas $d$-amphetamine was cleared more slowly (mean $t_{1 / 2}, 8.6-15.0 \mathrm{~h}$ ). Exposure to $d$-amphetamine (maximum plasma concentration $\left[C_{\max }\right]$ and area under the plasma concentration-time curve from zero to infinity $\left[\mathrm{AUC}_{0-\infty}\right]$ ) were linearly proportional to LDX dose in children with ADHD within the therapeutic dose range (Table 2; Fig. 3a) [14] and in healthy adults at therapeutic and supratherapeutic doses $(N=20)$ [16].

\subsection{Comparison of $d$-Amphetamine Pharmacokinetics Following Oral LDX or Immediate-Release $\boldsymbol{d}$-Amphetamine}

Data directly comparing $d$-amphetamine pharmacokinetic profiles following oral administration of LDX or an IR $d$ amphetamine formulation are limited to a single-blind study involving a supratherapeutic dose of LDX in three cohorts of adults with histories of stimulant abuse $(N=12)$. The mean plasma $d$-amphetamine $T_{\max }$ in each cohort occurred $1 \mathrm{~h}$ later following administration of LDX $100 \mathrm{mg}$ (range 3.78-4.25 h) than for an equivalent dose of $d$-amphetamine sulfate $(40 \mathrm{mg} ; 1.88-2.74 \mathrm{~h}$ ) [17], suggesting that the systemic delivery of $d$-amphetamine from LDX is dependent upon the rate-limiting conversion of the parent molecule.

\subsection{Consistency of Exposure to $d$-Amphetamine Following LDX Administration}

Reliable symptom control by LDX is dependent on predictable and consistent exposure to $d$-amphetamine. Table 2 shows that $d$-amphetamine exposure was generally consistent across studies for a given LDX dose and age group, but that some age-related variability in $d$-amphetamine exposure was apparent. In children with ADHD, both $d$-amphetamine $C_{\max }$ and $\mathrm{AUC}_{0-\infty}$ for given doses of LDX were higher than in healthy adults, presumably reflecting differences in body size. Also, in healthy adults aged 55-74 years and 75 years and older, $d$-amphetamine exposure was higher and $t_{1 / 2}$ longer than in younger adults. This observation may be explained by a decrease in $d$ amphetamine clearance with age due to reduced renal function [18].

Within-study variability in $d$-amphetamine exposure may be expressed as the percentage coefficient of variation (\% $\mathrm{CV}=$ [parameter standard deviation/parameter mean] $\times 100$ ) for $C_{\max }, \mathrm{AUC}_{0-\mathrm{t}}$ and $\mathrm{AUC}_{0-\infty}$. Percent $\mathrm{CV}$ s below 30 are considered to represent low variability [19]. Table 2 shows that $\% \mathrm{CVs}$ for $d$-amphetamine exposure following doses of LDX were generally low (in the range 12.1-35.7), irrespective of age. In a single-dose study in healthy adults, both intra- and inter-individual \% $\mathrm{CV}$ s for $d$-amphetamine exposure $\left(\log C_{\max }\right.$ and $\log$ $\mathrm{AUC}_{0-\infty}$ ) were low following administration of a wide range of doses of LDX $(50-250 \mathrm{mg})$; all but the $50 \mathrm{mg}$ dose were supratherapeutic [16]. These data indicate that $d$-amphetamine is delivered consistently and predictably following LDX administration. In contrast, within-study inter-individual \% CVs for intact LDX exposure were nearly always higher than the equivalent values for $d$-amphetamine (Table 3).

\subsection{Gastrointestinal Factors Influencing $d$ - Amphetamine Pharmacokinetics Following LDX Administration}

Factors that influence a drug's rate of transit through, and uptake from, the GI tract include the presence of food and pH [20-22]. In a single-dose crossover study, Krishnan and Zhang [23] reported that $d$-amphetamine $T_{\max }$ was delayed by approximately $1 \mathrm{~h}$ in healthy adults $(N=18)$ administered LDX $70 \mathrm{mg}$ following a high-fat meal compared with those who fasted; there were no significant differences in $C_{\max }, \mathrm{AUC}_{0-\infty}$ or $t_{1 / 2}$ (Table 2; high-fat meal defined in legend). In contrast, while $T_{\max }$ for intact LDX also exhibited a significant delay of approximately $1 \mathrm{~h}, C_{\max }$ was significantly lower and $t_{1 / 2}$ significantly longer in the fed than in the fasted state, although $\mathrm{AUC}_{0-\infty}$ was unaffected $(N=8)$ (Table 3) [24]. Following orally administered extended-release mixed amphetamine salts (MAS $\mathrm{XR}$ ), however, the mean $T_{\max }$ of plasma $d$-amphetamine was reported as approximately $2.5 \mathrm{~h}$ longer in fed than in fasted individuals, with $C_{\max }$ and $\mathrm{AUC}_{0-\infty}$ modestly lower $[21,22]$. These results suggest that LDX hydrolysis, rather than GI transit and uptake, is the dominant factor in
Table 1 Interpreting pharmacokinetic parameters

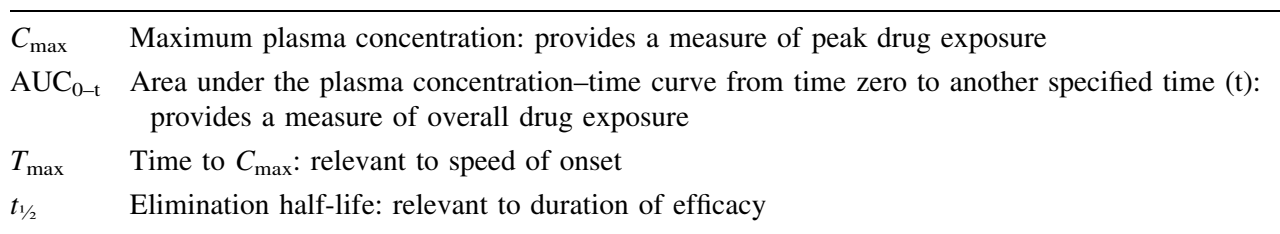


(a)

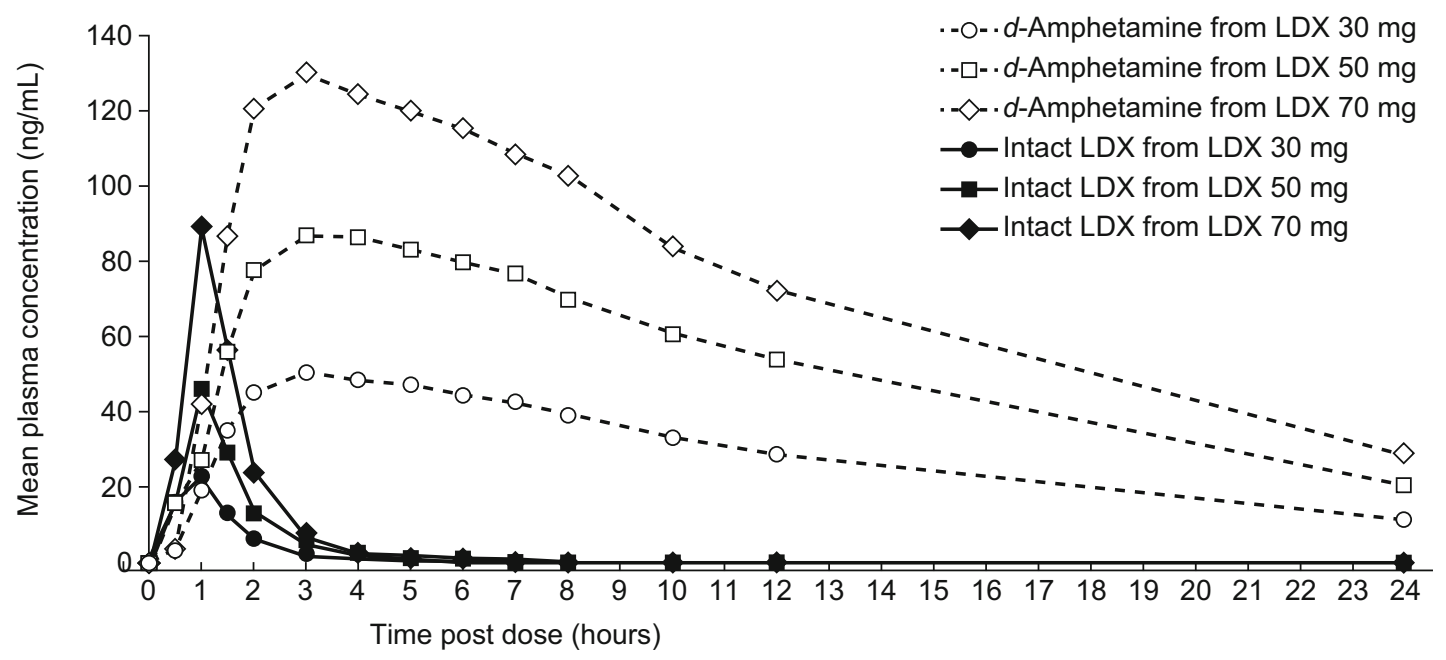

(b)

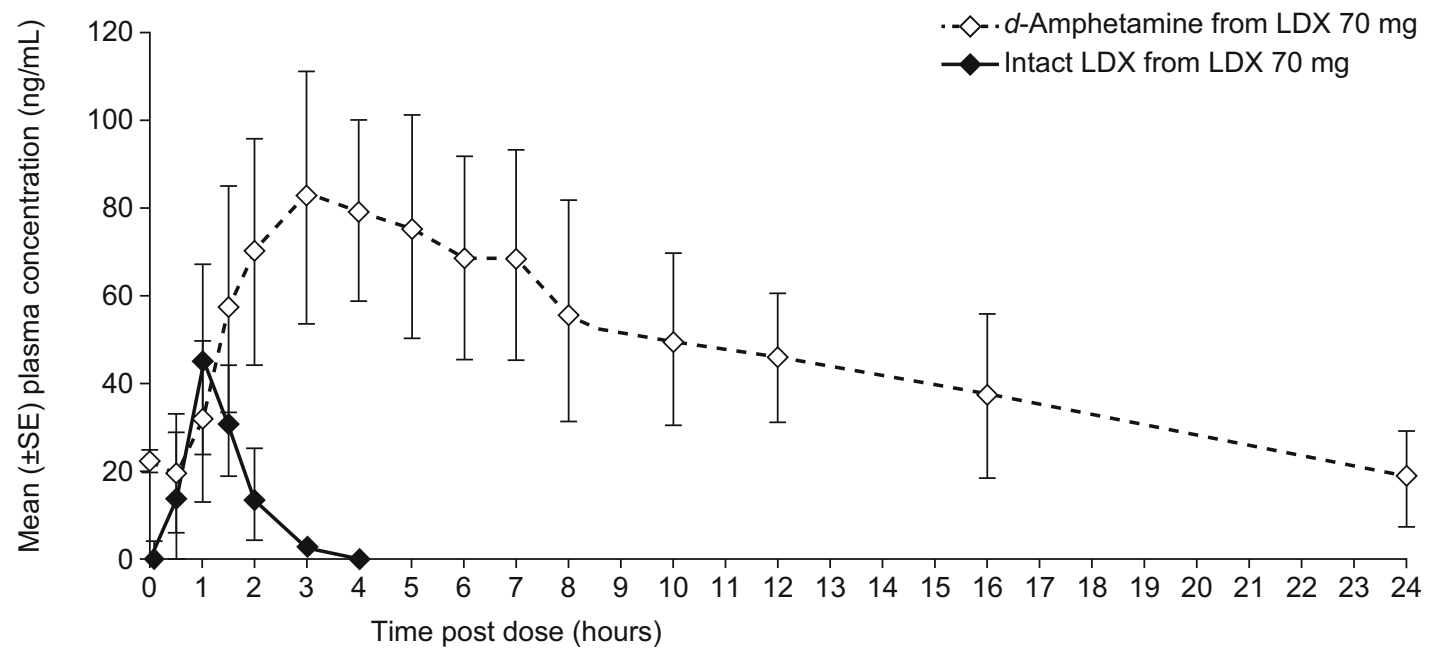

(c) Assessment CPRS-R [8] CPRS-R [62]

SKAMP and PERMP [24] SKAMP and PERMP [57] SKAMP [59]

PERMP [60] ${ }^{*}$

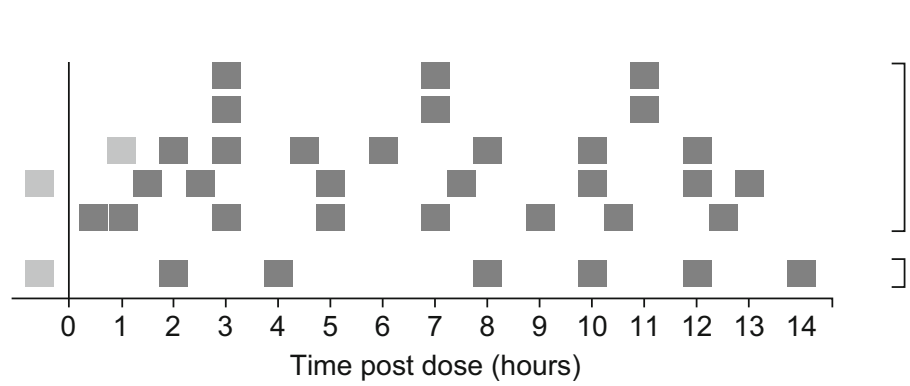

Baseline assessment Assessment

Children

Adults

Fig. 3 Pharmacokinetic profiles of plasma LDX and $d$-amphetamine a after a single oral dose of LDX in children with $\operatorname{ADHD}(N=17)$ [14] (Reproduced from 'Pharmacokinetics of lisdexamfetamine dimesylate and its active metabolite, d-amphetamine, with increasing oral doses of lisdexamfetamine dimesylate in children with attentiondeficit/hyperactivity disorder: a single-dose, randomized, open-label, crossover study', Boellner SW et al. Clinical Therapeutics 2010;32:252-64. (C2010 Excerpta Medica Inc. Reproduced with permission from Elsevier), b on day 7 of daily oral LDX dosing in healthy adults $(N=11)$ [15] (Krishnan SM and Stark JG, Current Medical Research and Opinion 2008;24:33-40, copyright (C2008
Informa Healthcare. Adapted with permission of Informa Healthcare), and $\mathbf{c}$ timings of symptomatological (SKAMP, CPRS-R) or functional (PERMP) assessments in studies of the efficacy of LDX throughout the day $[8,24,57,59,60,62]$. Asterisk Effect sizes for LDX versus placebo in these studies are presented in Fig. 4. Biederman et al. [24] used a post-dose time point as baseline. ADHD attention-deficit/ hyperactivity disorder, $C P R S-R$ Connors' Parent Rating Scale-Revised, $L D X$ lisdexamfetamine dimesylate, PERMP Permanent Product Measure of Performance, SKAMP Swanson, Kotkin, Agler, M-Flynn, and Pelham 


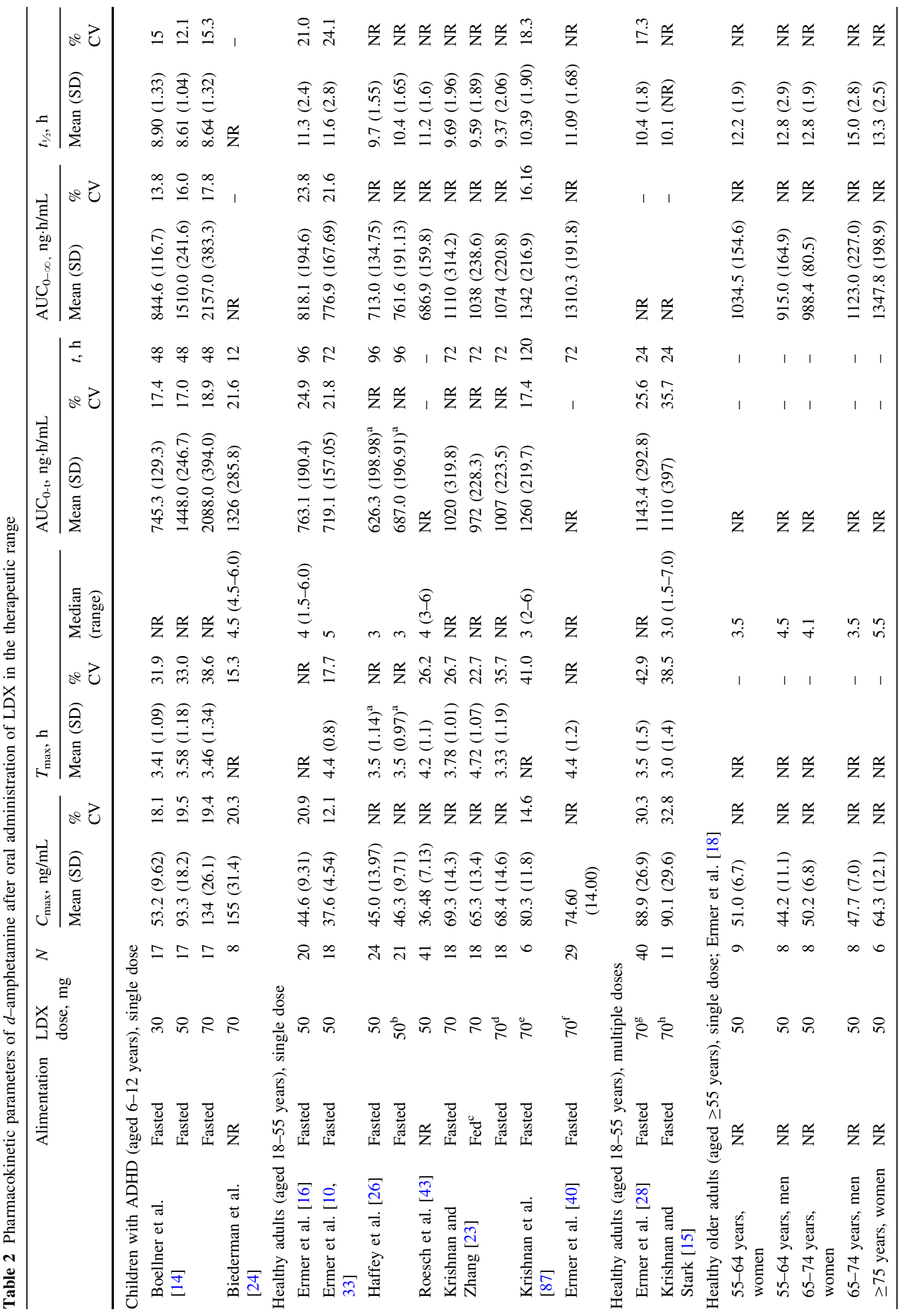




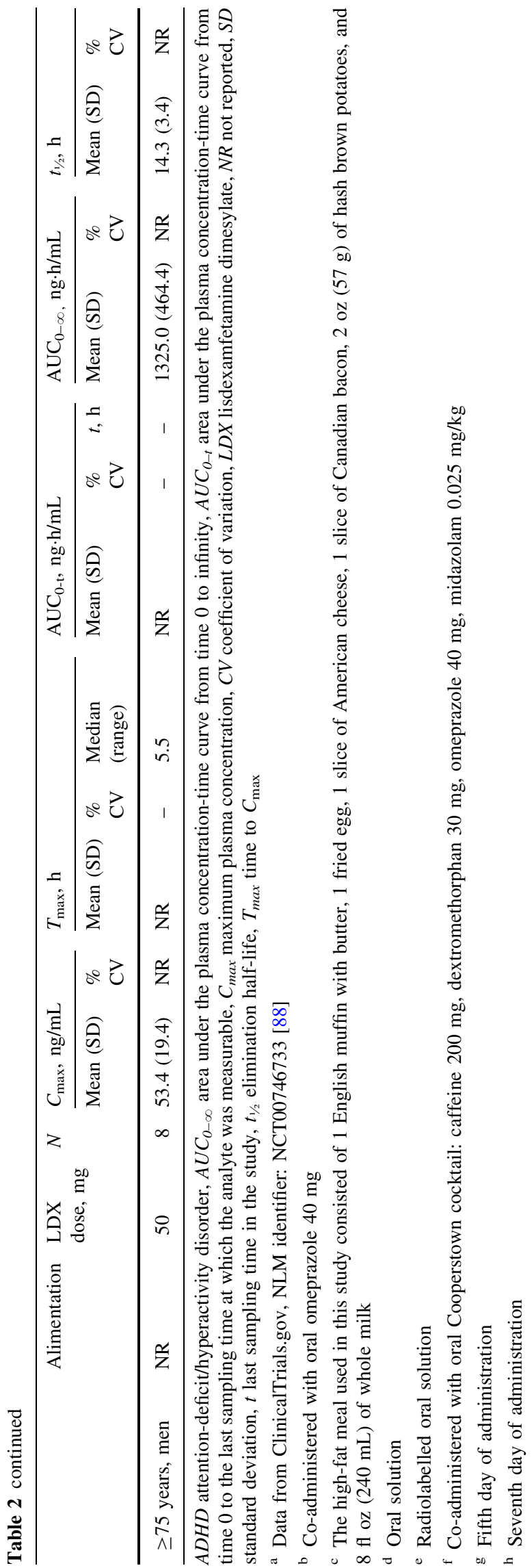

determining the $d$-amphetamine exposure profile following oral administration of LDX.

GI disorders, including ulcers and dyspepsia, are commonly treated using proton pump inhibitors, such as omeprazole, to suppress acid secretion by the stomach mucosa and thereby increase the $\mathrm{pH}$. The inhibition of gastric acid secretion may, however, interfere with the absorption of drugs for which $\mathrm{pH}$ is an important determinant of bioavailability [25], such as MAS XR which uses $\mathrm{pH}$-sensitive beaded technology to achieve phased release. Haffey et al. [26] reported that the median $T_{\max }$ for total amphetamine was approximately $2 \mathrm{~h}$ shorter in healthy adults when MAS XR was co-administered with omeprazole $\left(T_{\max }, 2.75 \mathrm{~h}\right)$ than when administered alone $\left(T_{\max }, 5\right.$ h) $(N=24)$. In the same study, $d$-amphetamine pharmacokinetic parameters remained largely unaltered when LDX was co-administered with oral omeprazole (Table 2). Thus, these results indicate that, unlike MAS XR, LDX provided an amphetamine exposure profile that was unaffected by administration of a proton pump inhibitor.

LDX is soluble in water [9] and can, therefore, be administered as a solution or mixed into food to individuals who experience difficulty in swallowing capsules, or in circumstances when the monitoring of drug consumption is a requirement. This differs from other long-acting stimulant formulations which rely on mechanical phased release of the active drug from a capsule. In another study (NCT01890785), similar values of $d$-amphetamine $C_{\max }$ and $\mathrm{AUC}_{0-96 \mathrm{~h}}$ were seen when oral LDX $70 \mathrm{mg}$ was administered to healthy adults as capsules, or capsule contents were dissolved in orange juice or mixed into vanilla yogurt [27]; in addition administration with yogurt delayed $T_{\max }$ by only $0.4 \mathrm{~h}$ compared with the fasted state [9].

To summarise, the above LDX single-dose studies suggest that the hydrolysis of LDX to $d$-amphetamine in the blood is the rate-limiting step, rather than the uptake of the parent drug from the GI tract. This leads to consistent intra- and inter-individual $d$-amphetamine exposure profiles.

\subsection{Multiple Once-Daily Dosing of LDX}

In a study of multiple once-daily dosing of LDX $70 \mathrm{mg}$ in healthy adults, Krishnan and Stark [15] observed that steady-state plasma $d$-amphetamine concentrations were achieved by day five $[15,28]$. At steady state, pre-dose plasma $d$-amphetamine concentrations were approximately $20 \mathrm{ng} / \mathrm{mL}$, and $C_{\max }$ following each daily dose was approximately $90 \mathrm{ng} / \mathrm{mL}$ (Fig. 3b), moderately higher than following a single $70 \mathrm{mg}$ dose in adults (Table 2) [15]. The values for $d$-amphetamine $T_{\max }, t_{1 / 2}$ and $\mathrm{AUC}_{0-\infty}$ were similar following a single dose of LDX, regardless of 


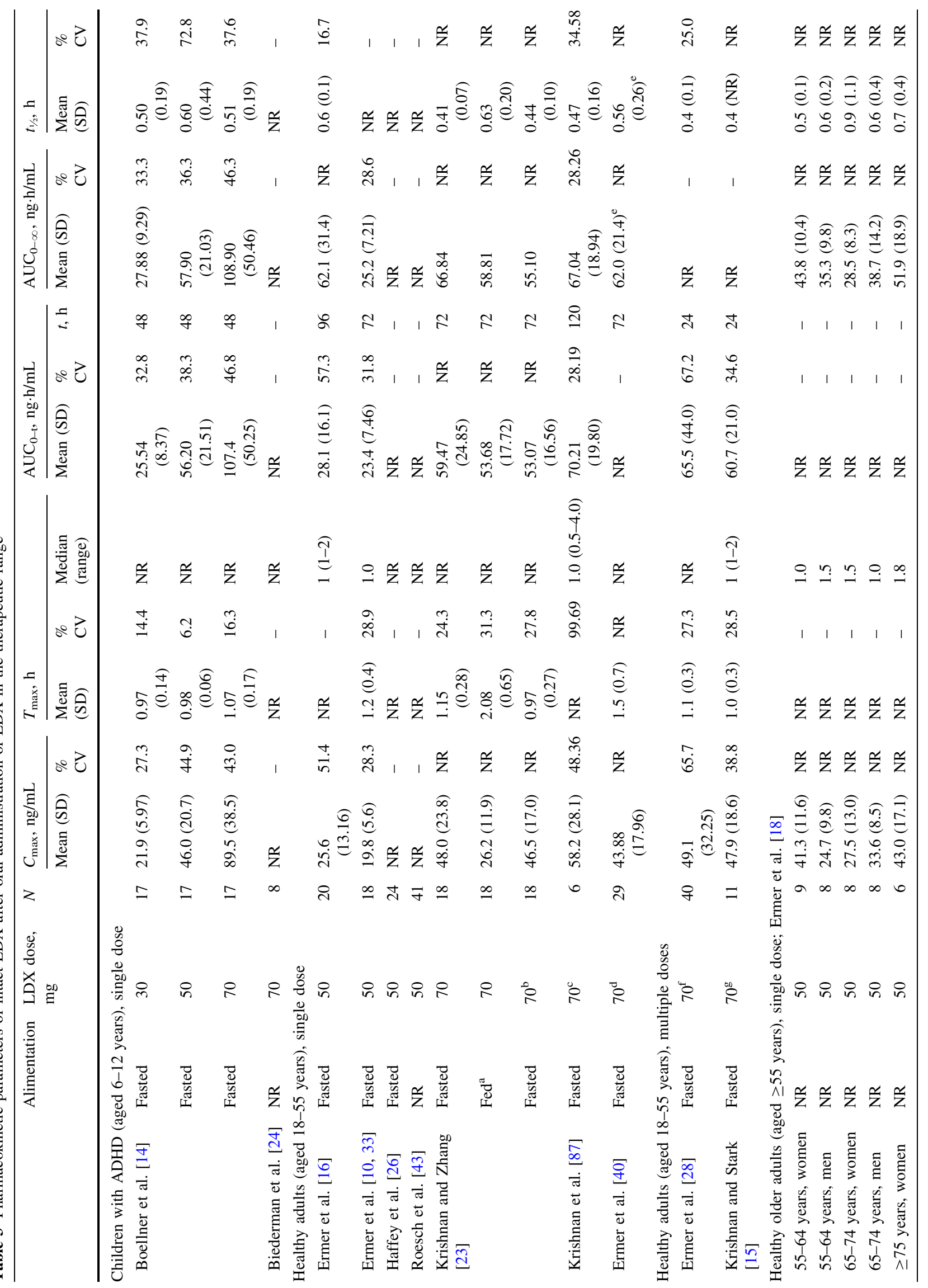




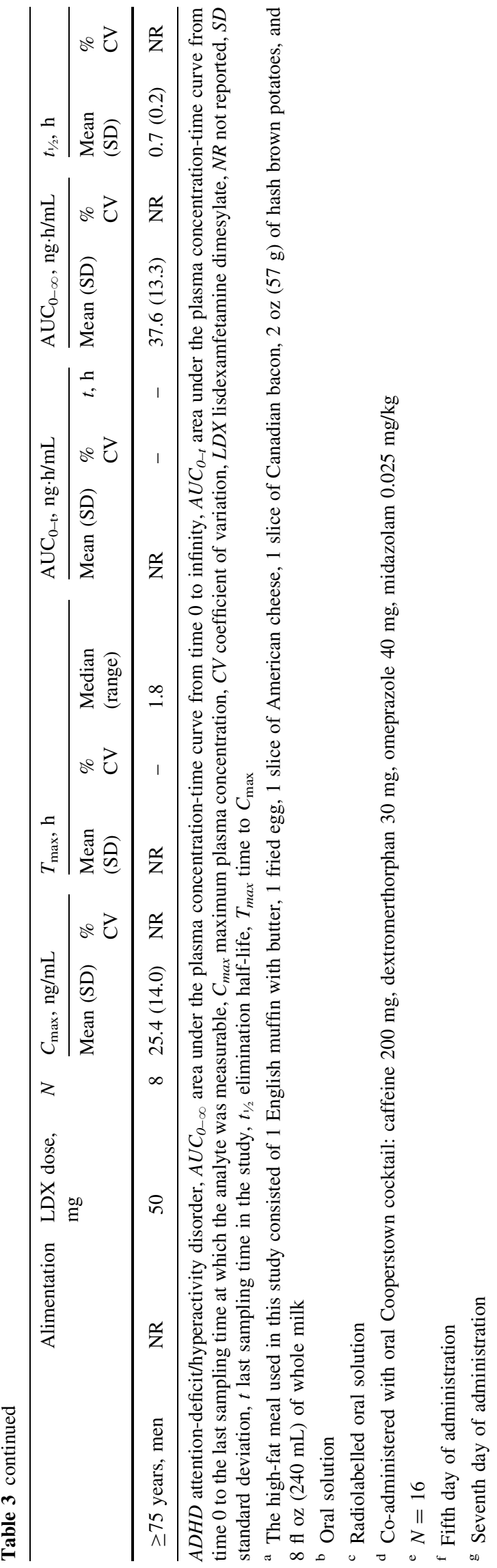

whether steady state had previously been reached (Table 2). These results suggest that $d$-amphetamine exposure reaches therapeutic levels after a single dose of LDX and that systemic concentrations of $d$-amphetamine do not markedly increase with multiple once-daily dosing.

\subsection{Effect of Route of Administration of LDX or Immediate-Release $d$-Amphetamine on Plasma $d$-Amphetamine Pharmacokinetics}

The abuse of stimulants often involves intranasal or intravenous administration to shorten stimulant blood plasma $T_{\max }$ and increase $C_{\max }$, thereby enhancing the euphorigenic potential [29-31]. The pharmacokinetics of intravenous LDX compared with intravenous $d$-amphetamine were evaluated in a single-dose, crossover study in adults with a history of stimulant abuse $(N=9)$. Mean (SD) $d$ amphetamine $T_{\max }$ was shorter and $C_{\max }$ higher following intravenous IR $d$-amphetamine (20 mg; $T_{\max }, 0.8 \mathrm{~h} \mathrm{[1.3];}$ $C_{\max }, 105 \mathrm{ng} / \mathrm{mL}$ [91.4]) than after an equivalent dose of intravenous LDX (50 mg; $T_{\max }, 2.5 \mathrm{~h} \mathrm{[1.5];} C_{\max }, 38.9 \mathrm{ng} /$ $\mathrm{mL}$ [8.1]) [32]. This more gradual approach to a lower peak plasma $d$-amphetamine concentration for LDX compared with IR $d$-amphetamine presumably resulted from ratelimited hydrolysis of the prodrug in the blood. The impact of the route of administration was further explored in a single-dose, crossover study in healthy adults, which found no difference in $d$-amphetamine pharmacokinetics following oral and intranasal administration of LDX $50 \mathrm{mg}$ $(N=18)$ (Table 4) [33].

\subsection{Impact of Compromised Erythrocytes and Haematocrit Level on the Generation of $d$ - Amphetamine from LDX}

The effects on LDX metabolism of moderately compromised erythrocytes and low haematocrit have been investigated in vitro. The rate of LDX hydrolysis was similar in blood from donors with or without sickle cell disease [34]. Furthermore, the rate of LDX hydrolysis was haematocritdependent, but substantial $d$-amphetamine production was still observed at $10 \%$ of normal haematocrit [11]. These results suggest that LDX biotransformation is unaffected by clinically relevant variations in erythrocyte viability and levels [11, 34].

\subsection{Potential for Drug-Drug Interactions}

In vitro evidence indicates that $L D X$ itself does not interact with the major cytochrome P450 (CYP) isoforms commonly inhibited or induced by therapeutic drugs (CYP1A2, 2A6, 2B6, 2C9, 2C19, 2D6, 3A4/5 [35] and 2C8 [36]), and does not inhibit or act as a substrate for human 


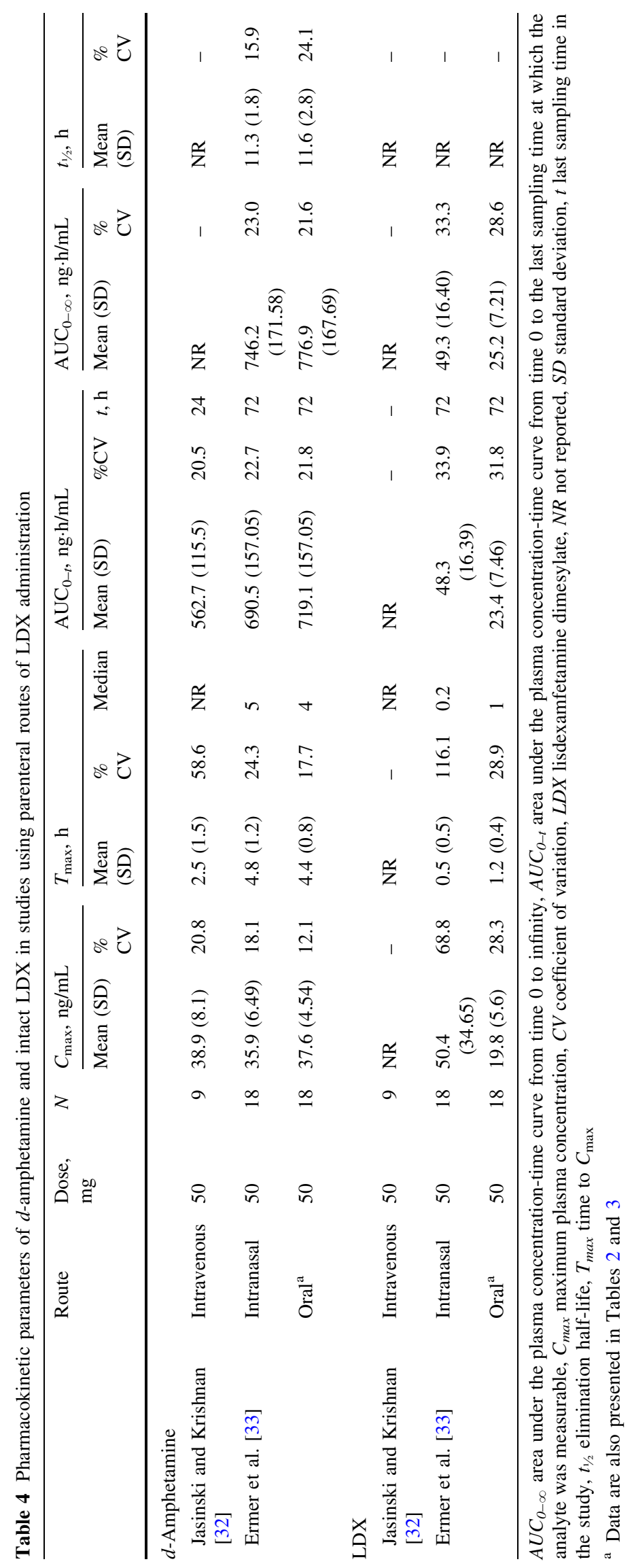


$\longrightarrow$ SKAMP total

- PERMP attempted

$-\triangle$ PERMP correct
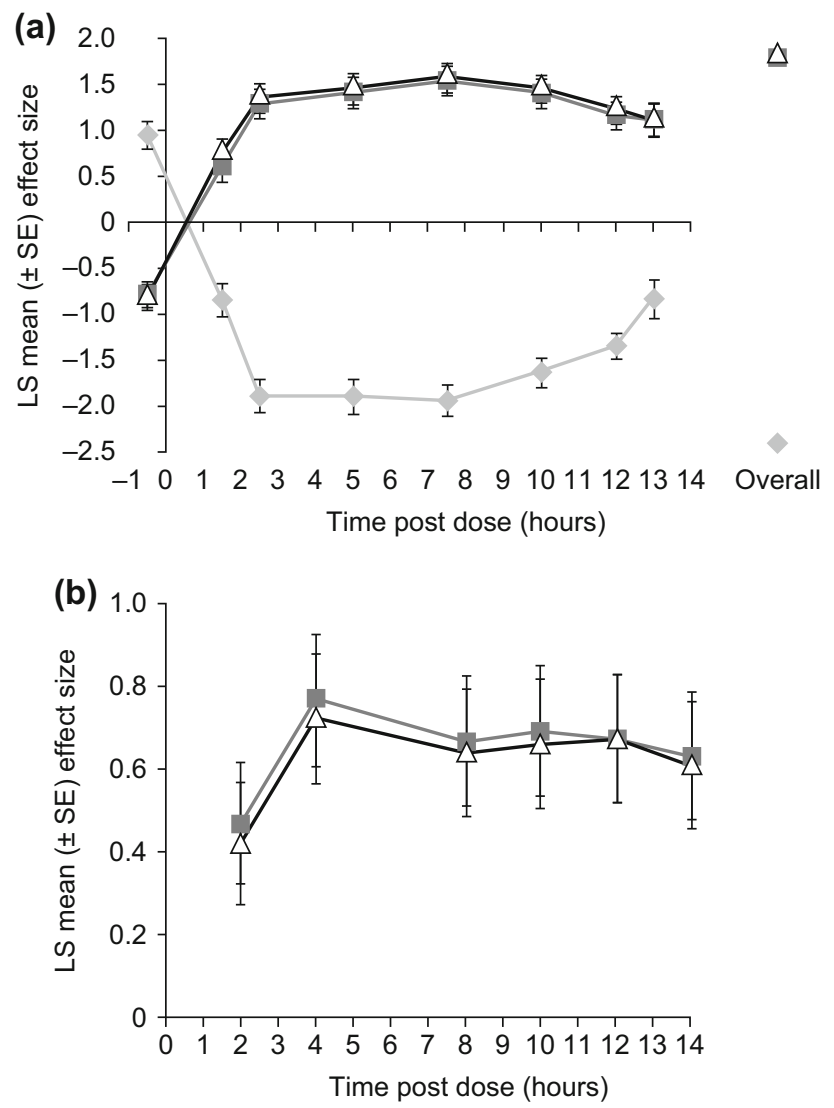

Fig. 4 Analyses of the effect sizes of LDX versus placebo in a children with ADHD in an analogue classroom study (post-hoc) [58] and $\mathbf{b}$ adults with ADHD in a model workplace study [61] (Effect size of lisdexamfetamine dimesylate in adults with attention-deficit/ hyperactivity disorder, Wigal T et al. Postgraduate Medicine 2011 123:169-76, Informa Healthcare. Reprinted by permission of the publisher Informa healthcare http://informahealthcare.com/) LDX demonstrated significant improvement versus placebo, by effect size, at all post-dose time points in both studies. For PERMP, positive effect sizes indicate superiority over placebo; for SKAMP, negative effect sizes indicate superiority over placebo. $A D H D$ attention-deficit/ hyperactivity disorder, $L S$ least-squares, $S E$ standard error, $S E M$ standard error of the mean, SKAMP Swanson, Kotkin, Agler, M-Flynn, and Pelham, PERMP Permanent Product Measure of Performance

P-glycoprotein [36]. Other in vitro studies suggest that amphetamine weakly inhibits CYP2D6 [37] and 2A6 [38], and that its metabolites weakly inhibit CYP2D6, 1A2 and 3A4 [39].

In an in vivo study designed to investigate whether LDX affects the activity of CYP isoforms, the following drugs were administered to healthy individuals in the form of a Cooperstown cocktail with or without LDX: caffeine (a CYP1A2 substrate), dextromethorphan (a CYP2D6 substrate), midazolam (a CYP3A substrate) and omezaprole (the proton pump inhibitor described in the 'gastrointestinal factors' section and a CYP2C19 substrate). The pharmacokinetic profiles of $d$-amphetamine and LDX were similar to those observed in other studies (Tables 2, 3). Furthermore, LDX had no effect on the activity of CYP1A2, 2D6 or $3 \mathrm{~A}$ as determined by the $C_{\max }$ and $\mathrm{AUC}_{0-}$ $\infty$ of their respective substrates. For omeprazole a small decrease in $C_{\max }$ was observed, possibly indicating that LDX may have an effect either on CYP2C19 activity or on omeprazole absorption [40].

In vivo, co-administration of LDX with extended-release guanfacine, an $\alpha_{2}$-adrenoreceptor agonist that is approved in the USA [41] and Canada [42] for treatment of ADHD in combination with psychostimulants (and is a CYP3A4 substrate), led to no clinically meaningful difference in $d$-amphetamine or guanfacine pharmacokinetic profiles [43]. When LDX was co-administered with venlafaxine, a serotonin-noradrenaline reuptake inhibitor that is predominantly metabolised by CYP2D6 [44], there was no change in $d$-amphetamine pharmacokinetics. Although a small decrease in exposure to $O$-desmethylvenlafaxine (the active metabolite of venlafaxine) was observed, total exposure to venlafaxine plus $O$-desmethylvenlafaxine was unaffected [28].

\section{Pharmacodynamics of $d$-Amphetamine Delivered by Hydrolysis of LDX}

\subsection{Efficacy Throughout the Day Following an Early-Morning Dose of LDX}

The pharmacokinetics of $d$-amphetamine delivered by hydrolysis of LDX are reflected in the duration of the therapeutic action following an early-morning dose of LDX. Although the shorter $d$-amphetamine $T_{\max }$ for IR amphetamine compared with LDX leads to more rapid initial symptom control, the therapeutic effects of IR amphetamine and IR MAS do not extend beyond 4-6 $\mathrm{h}$ in children with ADHD [2-5, 45] or hyperkinetic disorder [46, 47]. This necessitates multiple daily doses of IR amphetamine or IR MAS to extend symptom control into the afternoon and evening [2].

Extended-release formulations have been developed to provide prolonged drug delivery [3, 48-55]. To date, LDX is the only prodrug ADHD medication, the only long-acting stimulant that does not rely on mechanical phased release, and the only stimulant for which efficacy in treating the symptoms of ADHD has been demonstrated beyond $12 \mathrm{~h}$ post-dose [56]. The duration of action of LDX following an early-morning dose has been evaluated in a series of model environment studies and phase III clinical trials conducted in children, adolescents and adults with 
ADHD. Figure 3 illustrates how the timings of efficacy assessments in these studies (Fig. 3c) relate to the pharmacokinetic profiles of intact LDX and $d$-amphetamine following a single dose of LDX 30, 50 and $70 \mathrm{mg}$ (Fig. 3a) or after the last of seven daily doses of LDX $70 \mathrm{mg}$ (Fig. 3b).

Two randomised, double-blind, placebo-controlled, crossover analogue classroom studies in children (aged 6-12 years) with ADHD have studied changes in scores on the Swanson, Kotkin, Agler, M-Flynn, and Pelham (SKAMP) and Permanent Product Measure of Performance (PERMP) scales. In the first study $(N=117)$, dose-optimised LDX led to marked, sustained and statistically significant $(p<.005)$ improvements in the SKAMP Deportment and Attention subscale scores and PERMP scale scores from $1.5 \mathrm{~h}$ to at least $13 \mathrm{~h}$ post-dose (last assessment) compared with placebo [57]. Post hoc analyses showed that effect sizes in favour of LDX over placebo remained large from $2.5 \mathrm{~h}$ until at least $13 \mathrm{~h}$ post-dose (range 0.84-1.11) for SKAMP total and PERMP Attempted and Correct scores (Fig. 4a) [58]. In the second classroom study $(N=52)$, significant $(p<.001)$ improvements compared with placebo in SKAMP Deportment and Attention subscale scores and PERMP Attempted and Correct scores were maintained for $12 \mathrm{~h}$ (last assessment) after an optimised dose of LDX [24]. Additionally, a summer camp study in children with ADHD $(N=25)$ investigated the relative effectiveness of dose-optimised LDX, intensive behavioural intervention and a combination of both treatments. Compared with intensive behavioural intervention alone, the overall magnitude of changes in SKAMP scores were large for both LDX alone (effect size, 1.16) and combined treatment (effect size, 1.14), and the benefits were maintained until the last assessment $(12.5 \mathrm{~h}$ post-dose) [59].

The duration of action of LDX in adults with ADHD was evaluated in a randomised, double-blind, placebocontrolled, crossover study in a simulated workplace environment $(N=127)$. Compared with placebo, both absolute $(p \leq .0017)$ and change from baseline $(p<.001)$ PERMP total scores were significantly improved at all post-dose assessments from 2 to $14 \mathrm{~h}$ [60]. Medium-tolarge least-squares mean model-based effect sizes for PERMP Attention and Correct scores were maintained for up to $14 \mathrm{~h}$ after LDX administration (Fig. 4b) [61].

Two randomised, double-blind, phase III clinical trials have used the Conners' Parent Rating Scale-Revised (CPRS-R) to assess the duration of therapeutic response in children and adolescents (6-17 years) with ADHD. Although the range of post-dose assessment time points was not as extensive as in the model environment studies and the outcomes relied on parent/caregiver reports rather than direct observations, these phase III clinical trials enrolled large patient numbers and provide robust data. At endpoint in a 7-week, dose-optimised, European trial in children and adolescents with ADHD $(N=336)$, differences between LDX and placebo in least-squares mean change from baseline in CPRS-R total score were statistically significant $(p<.001)$ at $10 \mathrm{am}, 2 \mathrm{pm}$ and $6 \mathrm{pm}$ following an early-morning dose (approximately $7 \mathrm{am}$ ), with effect sizes maintained in the range 1.30-1.42 [62]. Similarly, in a 4-week, fixed-dose, US trial in children (6-12 years) with ADHD $(N=290)$, the reductions in CPRS-R scores were significantly greater for LDX 30,50 and $70 \mathrm{mg}$ than for placebo at all three assessment times $(p<.001)[8]$.

\subsection{Safety}

The safety profile of LDX, including treatment-emergent adverse events (TEAEs), vital sign changes and laboratory signs is consistent with the known safety profile of stimulants used in the treatment of ADHD, and has been recently reviewed [63]. Here we further review in greater detail two safety concerns associated with stimulants that are particularly pertinent to the pharmacokinetic and pharmacodynamic characteristics of LDX: effects on sleep and the potential for abuse, misuse and diversion as determined by drug-liking scores.

\subsubsection{Effect of LDX on Sleep}

Sleep-related TEAEs are a consistent finding in clinical trials of stimulant medications in individuals of all ages with ADHD [64, 65]. With the duration of efficacy of LDX extending at least into the evening, the effect on sleeprelated TEAEs is of clinical interest, although the proportion of patients who experience TEAEs during a clinical study does not provide information about the time of onset or the duration of the TEAE. The incidence of insomnia as a TEAE in short-term, randomised, double-blind, parallelgroup, phase III clinical trials of LDX ranges from 11.2 to $18.8 \%$ in children and/or adolescents [8, 66-68], and from 12.7 to $19.3 \%$ in adults $[69,70]$, compared with rates of $4.8 \%$ or below in individuals receiving placebo. In longerterm safety and efficacy extension studies of at least 6 months' duration, the incidence of insomnia as a TEAE in individuals with ADHD who were receiving LDX was similar to that in the short-term trials: $17.3 \%$ in children [71], $12.1 \%$ in adolescents [72], $14.1 \%$ in children and adolescents [73], and $19.5 \%$ in adults [74].

The relationships between stimulant treatment, the incidence of sleep-related TEAEs, and sleep disturbance are not, however, straightforward because ADHD itself is associated with disturbance of sleep [75-77], which may be exacerbated in the evening if the efficacy of medication 
wanes $[64,65,78]$. In a short-term, phase III trial in adults with ADHD, despite sleep-related TEAEs being reported by a higher proportion of individuals receiving LDX (109/ $358,30.4 \%)$ than by those taking placebo $(9 / 62,14.5 \%)$, there was no difference at endpoint in the mean global Pittsburgh Sleep Quality Instrument (PSQI) score, a subjective assessment of sleep quality, among those reporting sleep-related TEAEs. Indeed, significant improvements were observed in the LDX group compared with the placebo group in one of the PSQI components (daytime functioning, $p=.0001$ ), leading the authors to caution against relying on self-reported TEAEs alone as an indication of the effect of stimulant medications on sleep [79]. In a post hoc analysis of this study, a greater proportion of individuals in the LDX group (20.9 \%) than in the placebo group $(8.2 \%)$ demonstrated better sleep at endpoint than at baseline, and the relationship between treatment group and endpoint PSQI score was statistically significant $(p=.03)$ [80]. Furthermore, the relationship between clinically meaningful improvements in the symptoms of ADHD (defined as Clinical Global Impressions-Improvement [CGI-I] scores of 1 or 2) and improved sleep (i.e. decreased PSQI scores) was statistically significant $(p=.0008)$ [80]. In a laboratory sleep study [81], children (6-12 years) with ADHD $(N=24)$ were randomised $(2: 1)$ to receive an optimal dose of LDX (30,50 or $70 \mathrm{mg}$ based on therapeutic response during a 3-week open-label dose-optimisation period) or placebo. This study found no difference between individuals treated with LDX and those who received placebo in the polysomnographic assessments of latency to persistent sleep, wake time after sleep onset or total sleep time, but the number of awakenings after sleep was significantly decreased in those receiving LDX compared with participants who received placebo $(p<.0001)$ [81].

\subsubsection{Drug-Liking Scores for LDX Compared with Immediate-Release Amphetamine}

Drug-liking scores for LDX and IR $d$-amphetamine have been compared following oral and intravenous administration. On the primary measure of abuse liability in a double-blind, randomised, placebo-controlled, crossover study in individuals with a history of stimulant abuse $(N=36)$, the maximum change of the Drug Rating Questionnaire-Subject (DRQS) Liking scale score was not significantly different from placebo for oral LDX 50 and $100 \mathrm{mg}$, but was significant $(p<.001)$ at the supratherapeutic dose of $150 \mathrm{mg}$. In addition, participants significantly favoured oral IR $d$-amphetamine $40 \mathrm{mg}$ over an equivalent oral dose of LDX $(100 \mathrm{mg}, p<.05)$ but not LDX $150 \mathrm{mg}$. Furthermore, mean peak DRQS Liking scale scores for LDX were observed approximately 3 h (LDX 50 and $100 \mathrm{mg}$ ) or $4 \mathrm{~h}$ (LDX $150 \mathrm{mg}$ ) post-dose compared with 1.5-2 h post-dose for $d$-amphetamine $40 \mathrm{mg}$ [82].

In a second double-blind, randomised, placebo-controlled, crossover study conducted in individuals with a history of intravenous drug abuse $(N=9)$, maximum mean change in DRQS Liking scale scores for intravenous $d$ amphetamine $20 \mathrm{mg}$ (5.6 [standard error, 1.3]) was significantly $(p=.01)$ different from placebo (0.0 [1.3]), whereas scores for an equivalent intravenous dose of LDX $50 \mathrm{mg}(2.1$ [1.3]) did not differ from those for placebo $(p=.290)[32]$.

A post hoc analysis of these two drug-liking studies revealed that the subjective effects of LDX were not statistically significantly different when the drug was administered orally versus intravenously, in keeping with the broadly similar $d$-amphetamine pharmacokinetic profiles generated by LDX following oral and intravenous administration. In contrast, the subjective effects of IR amphetamine are both larger and more rapid in onset when administered intravenously than when administered orally [30]. These results, presumably reflecting the delayed $T_{\max }$ and lower $C_{\max }$ of the $d$-amphetamine pharmacokinetic profile, suggest that LDX may have a lower abuse potential than IR $d$-amphetamine.

Real-world data from a retrospective, observational case series of single-substance exposures to LDX (7,113 cases), dextroamphetamine/amphetamine IR (10,195 cases) or dextroamphetamine/amphetamine $\mathrm{XR}$ (6245 cases) is suggestive of a lower potential for abuse/misuse of LDX [83]. The study reports the odds of abuse/misuse was 2.3 (95\% confidence interval [CI] 2.0-2.4) times higher for dextroamphetamine/amphetamine IR than that for LDX and dextroamphetamine/amphetamine XR combined. The odds of abuse/misuse of dextroamphetamine/amphetamine $\mathrm{XR}$ was 1.9 (95\% CI 1.7-2.2) times higher than lisdexamfetamine.

\subsection{Why Might the Daily Duration of Efficacy of LDX Exceed that of Immediate-Release Amphetamine?}

Regardless of whether $d$-amphetamine is delivered via oral LDX or an IR formulation, the plasma $d$-amphetamine $t_{1 / 2}$ is approximately $10 \mathrm{~h}$, and the $\mathrm{AUC}_{0-\infty}$ is roughly similar for equivalent doses [2, 21, 26, 39, 84]. This raises the question of why the daily therapeutic duration of action of LDX is at least threefold that of IR amphetamine. The explanation may lie in the fact that the rate of increase in plasma $d$-amphetamine concentration is less steep (i.e. $T_{\max }$ is longer) and $C_{\max }$ is lower following oral administration of LDX compared with IR amphetamine [85], which suggests that acute tolerance (tachyphylaxis) could be a factor. 
Acute tolerance may be defined as a reduction in response to a drug over the course of a single exposure. In other words, for a given drug plasma concentration, therapeutic effects (and side effects) are greater when the drug plasma concentration is rising than when it subsequently declines. In terms of ADHD medication, acute tolerance to MPH has been observed, and understanding this phenomenon has led to improvements in long-acting formulations to treat ADHD [48-51, 54, 55]. Specifically, Swanson et al. [48] reported that a second bolus of MPH was less effective when given in the declining phase of plasma MPH concentration than in the ascending phase following an initial dose. This finding led to the discovery that a long-acting formulation delivering an ascending (rather than flat) profile of plasma MPH concentration was as effective in providing relief of ADHD symptoms through the day as three equally spaced doses of IR MPH per day [53].

Acute tolerance to the subjective effects of oral $d$-amphetamine $20 \mathrm{mg}$ has been observed in healthy adults [29], and the potential for LDX and IR $d$-amphetamine to cause acute tolerance has been investigated in rats by measuring plasma $d$-amphetamine concentrations, striatal extracellular concentrations of the neurochemical mediator dopamine and locomotor activity (as a behavioural outcome). The overall $d$-amphetamine exposure was similar for equivalent doses of both drugs, but delivery of the active drug via ratelimited hydrolysis resulted in a lower $d$-amphetamine $C_{\max }$ and delayed $T_{\max }$ for LDX than for IR $d$-amphetamine. Compared with IR $d$-amphetamine, the pharmacokinetic profile of plasma $d$-amphetamine produced by LDX led to behavioural activation that was less pronounced as extracellular striatal dopamine concentrations increased, but was maintained for longer as extracellular striatal dopamine concentrations decreased [86]. One potential explanation for these observations may be lower acute tolerance to $d$ amphetamine when generated from the prodrug than for IR $d$-amphetamine which, in turn, may be responsible for the extended daily duration of therapeutic action and reduced drug-liking effects of LDX compared with IR amphetamine formulations.

\section{Conclusions}

The hydrolysis of LDX produces a plasma $d$-amphetamine pharmacokinetic profile with lower $C_{\max }$, extended $T_{\max }$ and lower inter- and intra-individual variability than that produced by an equivalent dose of IR $d$-amphetamine. The therapeutic duration of action of LDX is considerably longer than that of an equivalent dose of IR $d$-amphetamine, possibly because reduced acute tolerance means that behavioural effects of LDX are maintained into the declining phase of the plasma $d$-amphetamine concentration-time curve. The safety profile of LDX is typical of the stimulant class of ADHD medications. The reduced drug-liking profile of LDX compared with IR $d$-amphetamine formulations at equivalent doses may reflect the lower plasma $d$-amphetamine $C_{\max }$ and delayed $T_{\max }$ of the prodrug that therefore reduce the euphorigenic potential. These pharmacokinetic and pharmacodynamic characteristics of LDX may be beneficial in the management of symptoms in patients with ADHD.

Acknowledgments Dr. M. Cottingham and Dr. H. Lang of Oxford PharmaGenesis Ltd provided writing assistance under the direction of the authors. Editorial assistance in editing, fact-checking, formatting, proofreading and submission was also provided by Oxford PharmaGenesis Ltd.

\section{Compliance with Ethical Standards}

Shire International GmbH provided funding to Oxford PharmaGenesis Ltd for writing and editorial support for this publication. J. C. Ermer and G. Frick are employees of Shire, and own stock and/or stock options. M. Pennick is a former employee of Shire and owns stocks and/or stock options. Shire develops and markets drugs to treat psychiatric disorders, including ADHD.

Open Access This article is distributed under the terms of the Creative Commons Attribution-NonCommercial 4.0 International License (http://creativecommons.org/licenses/by-nc/4.0/), which permits any noncommercial use, distribution, and reproduction in any medium, provided you give appropriate credit to the original author(s) and the source, provide a link to the Creative Commons license, and indicate if changes were made.

\section{References}

1. Swanson JM, Baler RD, Volkow ND. Understanding the effects of stimulant medications on cognition in individuals with attention-deficit hyperactivity disorder: a decade of progress. Neuropsychopharmacology. 2011;36(1):207-26. doi:10.1038/npp. 2010.160 .

2. Greenhill LL, Swanson JM, Steinhoff K, Fried J, Posner K, Lerner $\mathrm{M}$, et al. A pharmacokinetic/pharmacodynamic study comparing a single morning dose of adderall to twice-daily dosing in children with ADHD. J Am Acad Child Adolesc Psychiatry. 2003;42(10):1234-41. doi:10.1097/00004583200310000-00015.

3. McCracken JT, Biederman J, Greenhill LL, Swanson JM, McGough JJ, Spencer TJ, et al. Analog classroom assessment of a once-daily mixed amphetamine formulation, SLI381 (Adderall $\mathrm{XR})$, in children with ADHD. J Am Acad Child Adolesc Psychiatry. 2003;42(6):673-83. doi:10.1097/01.CHI.0000046863. 56865.FE.

4. Swanson JM, Wigal S, Greenhill LL, Browne R, Waslik B, Lerner $\mathrm{M}$, et al. Analog classroom assessment of Adderall in children with ADHD. J Am Acad Child Adolesc Psychiatry. 1998;37(5):519-26.

5. Pelham WE, Gnagy EM, Chronis AM, Burrows-MacLean L, Fabiano GA, Onyango AN, et al. A comparison of morning-only and morning/late afternoon Adderall to morning-only, twicedaily, and three times-daily methylphenidate in children with 
attention-deficit/hyperactivity disorder. Pediatrics. 1999;104(6):1300-11.

6. Ermer JC, Adeyi BA, Pucci ML. Pharmacokinetic variability of long-acting stimulants in the treatment of children and adults with attention-deficit hyperactivity disorder. CNS Drugs. 2010;24(12):1009-25. doi:10.2165/11539410-000000000-00000.

7. Hodgkins P, Shaw M, Coghill DR, Hechtman L. Amfetamine and methylphenidate medications for attention-deficit/hyperactivity disorder: complementary treatment options. Eur Child Adolesc Psychiatry. 2012;21(9):477-92. doi:10.1007/s00787-012-0286-5.

8. Biederman J, Krishnan S, Zhang Y, McGough JJ, Findling RL. Efficacy and tolerability of lisdexamfetamine dimesylate (NRP104) in children with attention-deficit/hyperactivity disorder: a phase III, multicenter, randomized, double-blind, forced-dose, parallel-group study. Clin Ther. 2007;29(3):450-63.

9. Shire US Inc. Vyvanse ${ }^{\circledR}$ (lisdexamfetamine dimesylate) full prescribing information. 2015. http://pi.shirecontent.com/PI/ PDFs/Vyvanse_USA_ENG.pdf. Accessed 27 Feb 2015.

10. Ermer JC, Haffey MB, Doll WJ, Martin P, Sandefer EP, Dennis $\mathrm{K}$, et al. Pharmacokinetics of lisdexamfetamine dimesylate after targeted gastrointestinal release or oral administration in healthy adults. Drug Metab Dispos. 2012;40(2):290-7. doi:10.1124/dmd. 111.040691.

11. Pennick M. Absorption of lisdexamfetamine dimesylate and its enzymatic conversion to $d$-amphetamine. Neuropsychiatr Dis Treat. 2010;6:317-27.

12. Sharman J, Pennick M. Lisdexamfetamine prodrug activation by peptidase-mediated hydrolysis in the cytosol of red blood cells. Neuropsychiatr Dis Treat. 2014;10:2275-80. doi:10.2147/ndt. s70382.

13. Heal DJ, Smith SL, Findling RL. ADHD: current and future therapeutics. Curr Top Behav Neurosci. 2012;9:361-90. doi:10. 1007/7854_2011_125.

14. Boellner SW, Stark JG, Krishnan S, Zhang Y. Pharmacokinetics of lisdexamfetamine dimesylate and its active metabolite, $d$-amphetamine, with increasing oral doses of lisdexamfetamine dimesylate in children with attention-deficit/hyperactivity disorder: a single-dose, randomized, open-label, crossover study. Clin Ther. 2010;32(2):252-64. doi:10.1016/j.clinthera.2010.02.011.

15. Krishnan S, Stark JG. Multiple daily-dose pharmacokinetics of lisdexamfetamine dimesylate in healthy adult volunteers. Curr Med Res Opin. 2008;24(1):33-40. doi:10.1185/ $030079908 X 242737$.

16. Ermer JC, Homolka R, Martin P, Buckwalter M, Purkayastha J, Roesch B. Lisdexamfetamine dimesylate: linear dose-proportionality, low intersubject and intrasubject variability, and safety in an open-label single-dose pharmacokinetic study in healthy adult volunteers. J Clin Pharmacol. 2010;50(9):1001-10. doi:10. 1177/0091270009357346.

17. Jasinski DR, Krishnan S. Pharmacokinetics of oral lisdexamfetamine dimesylate (LDX; NRP104) versus d-amphetamine sulfate in healthy adults with a history of stimulant abuse (NRP104.A01). 2006. http://library.corporate-ir.net/library/17/ 179/179878/items/202579/6-18-06\%20Presentation\%20to\%20 CPDD\%20on\%20NRP104\%20A01\%20and\%20A03.pdf. 23 Oct 2013.

18. Ermer JC, Haffey MB, Richards C, Lasseter K, Adeyi B, Corcoran $\mathrm{M}$, et al. Double-blind, placebo-controlled, two-period, crossover trial to examine the pharmacokinetics of lisdexamfetamine dimesylate in healthy older adults. Neuropsychiatr Dis Treat. 2013;9:219-29. doi:10.2147/NDT.S38377.

19. Haidar SH, Davit B, Chen ML, Conner D, Lee L, Li QH, et al. Bioequivalence approaches for highly variable drugs and drug products. Pharm Res. 2008;25(1):237-41. doi:10.1007/s11095007-9434-x.
20. Watanalumlerd P, Christensen JM, Ayres JW. Pharmacokinetic modeling and simulation of gastrointestinal transit effects on plasma concentrations of drugs from mixed immediate-release and enteric-coated pellet formulations. Pharm Dev Technol. 2007;12(2):193-202. doi:10.1080/10837450701212750.

21. Tulloch SJ, Zhang Y, McLean A, Wolf KN. SLI381 (Adderall $\mathrm{XR}$ ), a two-component, extended-release formulation of mixed amphetamine salts: bioavailability of three test formulations and comparison of fasted, fed, and sprinkled administration. Pharmacotherapy. 2002;22(11):1405-15.

22. Auiler JF, Liu K, Lynch JM, Gelotte CK. Effect of food on early drug exposure from extended-release stimulants: results from the Concerta, Adderall XR Food Evaluation (CAFE) Study. Curr Med Res Opin. 2002;18(5):311-6. doi:10.1185/ 030079902125000840.

23. Krishnan S, Zhang Y. Relative bioavailability of lisdexamfetamine 70-mg capsules in fasted and fed healthy adult volunteers and in solution: a single-dose, crossover pharmacokinetic study. J Clin Pharmacol. 2008;48(3):293-302. doi:10.1177/ 0091270007310381.

24. Biederman J, Boellner SW, Childress A, Lopez FA, Krishnan S, Zhang Y. Lisdexamfetamine dimesylate and mixed amphetamine salts extended-release in children with ADHD: a double-blind, placebo-controlled, crossover analog classroom study. Biol Psychiatry. 2007;62(9):970-6. doi:10.1016/j.biopsych.2007.04.015.

25. AstraZeneca Pharmaceuticals LP. Prilosec ${ }^{\circledR}$ (omeprazole) full prescribing information. 2014. http://www1.astrazeneca-us.com/ pi/Prilosec.pdf. Accessed 21 May 2014.

26. Haffey MB, Buckwalter M, Zhang P, Homolka R, Martin P, Lasseter KC, et al. Effects of omeprazole on the pharmacokinetic profiles of lisdexamfetamine dimesylate and extended-release mixed amphetamine salts in adults. Postgrad Med. 2009;121(5):11-9. doi:10.3810/pgm.2009.09.2048.

27. Shire Development LLC. A phase 1, open-label, randomized, 3-period crossover study evaluating the relative bioavailability of SPD489 when the contents are emptied into a soft food and orange juice in healthy adult subjects. In: ClinicalTrials.gov [Internet]. Bethesda (MD): National Library of Medicine (US). 2000-[cited 12 September 2014]. http://www.clinicaltrials.gov/ show/NCT01890785 NLM Identifier: NCT01890785. Accessed 12 Sept 2014.

28. Ermer JC, Haffey MB, Richards C, Lasseter K, Roesch B, Purkayastha $\mathrm{J}$, et al. An open-label investigation of the pharmacokinetic profiles of lisdexamfetamine dimesylate and venlafaxine extended-release, administered alone and in combination, in healthy adults. Clin Drug Investig. 2013;33(4):243-54. doi:10.1007/s40261-013-0073-1.

29. Brauer LH, Ambre J, De Wit H. Acute tolerance to subjective but not cardiovascular effects of $d$-amphetamine in normal, healthy men. J Clin Psychopharmacol. 1996;16(1):72-6.

30. Heal DJ, Smith SL, Gosden J, Nutt DJ. Amphetamine, past and present-a pharmacological and clinical perspective. J Psychopharmacol. 2013;27(6):479-96. doi:10.1177/026988111 3482532.

31. Volkow ND, Swanson JM. Variables that affect the clinical use and abuse of methylphenidate in the treatment of ADHD. Am J Psychiatry. 2003;160(11):1909-18.

32. Jasinski DR, Krishnan S. Human pharmacology of intravenous lisdexamfetamine dimesylate: abuse liability in adult stimulant abusers. J Psychopharmacol. 2009;23(4):410-8. doi:10.1177/ 0269881108093841.

33. Ermer JC, Dennis K, Haffey MB, Doll WJ, Sandefer EP, Buckwalter $\mathrm{M}$, et al. Intranasal versus oral administration of lisdexamfetamine dimesylate: a randomized, open-label, two-period, crossover, single-dose, single-centre pharmacokinetic study in 
healthy adult men. Clin Drug Investig. 2011;31(6):357-70. doi:10.2165/11588190-000000000-00000.

34. Pennick M. Metabolism of the prodrug lisdexamfetamine dimesylate in human red blood cells from normal and sickle cell disease donors. J Drug Assess. 2013;2:17-20. doi:10.3109/ 21556660.2013.775132.

35. Krishnan S, Moncrief S. An evaluation of the cytochrome p450 inhibition potential of lisdexamfetamine in human liver microsomes. Drug Metab Dispos. 2007;35(1):180-4. doi:10.1124/dmd. 106.011973.

36. Hutson PH, Pennick M, Secker R. Preclinical pharmacokinetics, pharmacology and toxicology of lisdexamfetamine: a novel $d$ amphetamine pro-drug. Neuropharmacology. 2014;87:41-50. doi:10.1016/j.neuropharm.2014.02.014.

37. Bach MV, Coutts RT, Baker GB. Involvement of CYP2D6 in the in vitro metabolism of amphetamine, two $N$-alkylamphetamines and their 4-methoxylated derivatives. Xenobiotica Fate Foreign Compd Biol Syst. 1999;29(7):719-32. doi:10.1080/ 004982599238344.

38. Rahnasto M, Raunio H, Poso A, Juvonen RO. More potent inhibition of human CYP2A6 than mouse CYP2A5 enzyme activities by derivatives of phenylethylamine and benzaldehyde. Xenobiotica Fate Foreign Compd Biolo Syst. 2003;33(5):529-39. doi:10.1080/0049825031000085979.

39. DSM Pharmaceuticals Inc. ADDERALL ${ }^{\circledR}$ (CII). 2007. http:// www.accessdata.fda.gov/drugsatfda_docs/label/2007/011522s04 0lbl.pdf. Accessed 20 May 2014.

40. Ermer J, Corcoran M, Martin P. Lisdexamfetamine dimesylate effects on the pharmacokinetics of cytochrome P450 substrates in healthy adults in an open-label, randomized, Crossover study. Drugs R D. 2015;15(2):175-85. doi:10.1007/s40268-015-0090-z.

41. Shire US Inc. Intuniv ${ }^{\circledR}$ (guanfacine) extended-release tablets full prescribing information. 2014. http://pi.shirecontent.com/PI/ PDFs/Intuniv_USA_ENG.pdf. Accessed 27 Feb 2015.

42. Health Canada. Summary Basis of Decision (SBD) for Intuniv XR. Health Canada. 2013. http://www.hc-sc.gc.ca/dhp-mps/ prodpharma/sbd-smd/drug-med/sbd_smd_2013_intuniv_xr_150741eng.php. Accessed 27 Feb 2015.

43. Roesch B, Corcoran ME, Fetterolf J, Haffey M, Martin P, Preston $\mathrm{P}$, et al. Pharmacokinetics of coadministered guanfacine extended release and lisdexamfetamine dimesylate. Drugs $\mathrm{R} D$. 2013;13(2):119-28. doi:10.1007/s40268-013-0014-8.

44. Wyeth Pharmaceuticals Inc. Effexor XR® (venlafaxine hydrochloride) prescribing information. http://labeling.pfizer. com/showlabeling.aspx?ID=100. Accessed 15 Sept 2014.

45. McGough JJ, Biederman J, Greenhill LL, McCracken JT, Spencer TJ, Posner K, et al. Pharmacokinetics of SLI381 (ADDERALL XR), an extended-release formulation of Adderall. J Am Acad Child Adolesc Psychiatry. 2003;42(6):684-91. doi:10.1097/ 01.CHI.0000046850.56865.CB.

46. Brown GL, Hunt RD, Ebert MH, Bunney WE Jr, Kopin IJ. Plasma levels of d-amphetamine in hyperactive children. Serial behavior and motor responses. Psychopharmacology (Berl). 1979;62(2):133-40.

47. Brown GL, Ebert MH, Mikkelsen EJ, Hunt RD. Behavior and motor activity response in hyperactive children and plasma amphetamine levels following a sustained release preparation. J Am Acad Child Psychiatry. 1980;19(2):225-39.

48. Swanson JM, Gupta S, Guinta D, Flynn D, Agler D, Lerner M, et al. Acute tolerance to methylphenidate in the treatment of attention deficit hyperactivity disorder in children. Clin Pharmacol Ther. 1999;66(3):295-305. doi:10.1016/S00099236(99)70038-X.

49. Swanson JM, Volkow ND. Pharmacokinetic and pharmacodynamic properties of stimulants: implications for the design of new treatments for ADHD. Behav Brain Res. 2002;130(1-2):73-8.
50. Swanson JM. Long-acting stimulants: development and dosing. Can Child Adolesc Psychiatr Rev. 2005;14(Supplement 1):4-9.

51. Swanson JM, Lerner M, Wigal T, Steinhoff K, Greenhill L, Posner K, et al. The use of a laboratory school protocol to evaluate concepts about efficacy and side effects of new formulations of stimulant medications. J Atten Disord. 2002;6(Suppl 1):S73-88

52. Wigal SB, McGough JJ, McCracken JT, Biederman J, Spencer TJ, Posner KL, et al. A laboratory school comparison of mixed amphetamine salts extended release (Adderall XR) and atomoxetine (Strattera) in school-aged children with attention deficit/ hyperactivity disorder. J Atten Disord. 2005;9(1):275-89. doi:10. $1177 / 1087054705281121$.

53. Ermer JC, Shojaei A, Pennick M, Anderson CS, Silverberg A, Youcha SH. Bioavailability of triple-bead mixed amphetamine salts compared with a dose-augmentation strategy of mixed amphetamine salts extended release plus mixed amphetamine salts immediate release. Curr Med Res Opin. 2007;23(5):1067-75. doi:10.1185/030079907X182095.

54. Kimko H, Gibiansky E, Gibiansky L, Starr HL, Berwaerts J, Massarella $\mathrm{J}$, et al. Population pharmacodynamic modeling of various extended-release formulations of methylphenidate in children with attention deficit hyperactivity disorder via metaanalysis. J Pharmacokinet Pharmacodyn. 2012;39(2):161-76. doi:10.1007/s10928-011-9238-9.

55. Swanson JM, Gupta S, Lam A, Shoulson I, Lerner M, Modi N, et al. Development of a new once-a-day formulation of methylphenidate for the treatment of attention-deficit/hyperactivity disorder: proof-of-concept and proof-of-product studies. Arch Gen Psychiatry. 2003;60(2):204-11.

56. Brams M, Moon E, Pucci M, Lopez FA. Duration of effect of oral long-acting stimulant medications for ADHD throughout the day. Curr Med Res Opin. 2010;26(8):1809-25. doi:10.1185/ 03007995.2010.488553.

57. Wigal SB, Kollins SH, Childress AC, Squires L. A 13-hour laboratory school study of lisdexamfetamine dimesylate in school-aged children with attention-deficit/hyperactivity disorder. Child Adolesc Psychiatry Ment Health. 2009;3(1):17. doi:10. 1186/1753-2000-3-17.

58. Wigal SB, Kollins SH, Childress AC, Adeyi B. Efficacy and tolerability of lisdexamfetamine dimesylate in children with attention-deficit/hyperactivity disorder: sex and age effects and effect size across the day. Child Adolesc Psychiatry Ment Health. 2010;4:32. doi:10.1186/1753-2000-4-32.

59. Manos MJ, Caserta DA, Short EJ, Raleigh KL, Giuliano KC, Pucci NC, et al. Evaluation of the duration of action and comparative effectiveness of lisdexamfetamine dimesylate and behavioral treatment in youth with ADHD in a quasi-naturalistic setting. J Atten Disord. 2015;19(7):578-90. doi:10.1177/ 1087054712452915.

60. Wigal T, Brams M, Gasior M, Gao J, Squires L, Giblin J. Randomized, double-blind, placebo-controlled, crossover study of the efficacy and safety of lisdexamfetamine dimesylate in adults with attention-deficit/hyperactivity disorder: novel findings using a simulated adult workplace environment design. Behav Brain Funct. 2010;6:34. doi:10.1186/1744-9081-6-34.

61. Wigal T, Brams M, Gasior M, Gao J, Giblin J. Effect size of lisdexamfetamine dimesylate in adults with attention-deficit/hyperactivity disorder. Postgrad Med. 2011;123(2):169-76. doi:10. 3810/pgm.2011.03.2275.

62. Coghill DR, Banaschewski T, Lecendreux M, Zuddas A, Dittmann RW, Otero IH, et al. Efficacy of lisdexamfetamine dimesylate throughout the day in children and adolescents with attention-deficit/hyperactivity disorder: results from a randomized, controlled trial. Eur Child Adolesc Psychiatry. 2014;23(2):61-8. doi:10.1007/s00787-013-0421-y. 
63. Coghill DR, Caballero B, Sorooshian S, Civil R. A systematic review of the safety of lisdexamfetamine dimesylate. CNS Drugs. 2014;28(6):497-511. doi:10.1007/s40263-014-0166-2.

64. Lecendreux M, Konofal E, Bouvard M, Falissard B, MourenSimeoni MC. Sleep and alertness in children with ADHD. J Child Psychol Psychiatry Allied Discip. 2000;41(6):803-12.

65. Cortese S, Holtmann M, Banaschewski T, Buitelaar J, Coghill DR, Danckaerts M, et al. Practitioner review: current best practice in the management of adverse events during treatment with ADHD medications in children and adolescents. J Child Psychol Psychiatry Allied Discip. 2013;54(3):227-46. doi:10.1111/jcpp. 12036 .

66. Dittmann RW, Cardo E, Nagy P, Anderson CS, Bloomfield R, Caballero B, et al. Efficacy and safety of lisdexamfetamine dimesylate and atomoxetine in the treatment of attention-deficit/ hyperactivity disorder: a head-to-head, randomized, double-blind, phase IIIb study. CNS Drugs. 2013;27(12):1081-92. doi:10.1007/ s40263-013-0104-8.

67. Coghill DR, Banaschewski T, Lecendreux M, Soutullo C, Johnson M, Zuddas A, et al. European, randomized, phase 3 study of lisdexamfetamine dimesylate in children and adolescents with attention-deficit/hyperactivity disorder. Eur Neuropsychopharmacol. 2013;23(10):1208-18. doi:10.1016/j.euroneuro.2012.11. 012 .

68. Findling RL, Childress AC, Cutler AJ, Gasior M, Hamdani M, Ferreira-Cornwell MC, et al. Efficacy and safety of lisdexamfetamine dimesylate in adolescents with attention-deficit/hyperactivity disorder. J Am Acad Child Adolesc Psychiatry. 2011;50(4):395-405. doi:10.1016/j.jaac.2011.01.007.

69. Adler LA, Goodman DW, Kollins SH, Weisler RH, Krishnan S, Zhang Y, et al. Double-blind, placebo-controlled study of the efficacy and safety of lisdexamfetamine dimesylate in adults with attention-deficit/hyperactivity disorder. $J$ Clin Psychiatry. 2008;69(9):1364-73.

70. Adler LA, Dirks B, Deas PF, Raychaudhuri A, Dauphin MR, Lasser RA, et al. Lisdexamfetamine dimesylate in adults with attention-deficit/ hyperactivity disorder who report clinically significant impairment in executive function: results from a randomized, double-blind, placebo-controlled study. J Clin Psychiatry. 2013;74(7):694-702. doi:10.4088/JCP.12m08144.

71. Findling RL, Childress AC, Krishnan S, McGough JJ. Long-term effectiveness and safety of lisdexamfetamine dimesylate in school-aged children with attention-deficit/hyperactivity disorder. CNS Spectr. 2008;13(7):614-20.

72. Findling RL, Cutler AJ, Saylor K, Gasior M, Hamdani M, Ferreira-Cornwell $\mathrm{MC}$, et al. A long-term open-label safety and effectiveness trial of lisdexamfetamine dimesylate in adolescents with attention-deficit/hyperactivity disorder. J Child Adolesc Psychopharmacol. 2013;23(1):11-21. doi:10.1089/cap.2011. 0088.

73. Coghill DR, Banaschewski T, Lecendreux M, Johnson M, Zuddas A, Anderson CS, et al. Maintenance of efficacy of lisdexamfetamine dimesylate in children and adolescents with attentiondeficit/hyperactivity disorder: randomized-withdrawal study design. J Am Acad Child Adolesc Psychiatry. 2014;53(6):647-57 e1. doi:10.1016/j.jaac.2014.01.017.

74. Weisler R, Young J, Mattingly G, Gao J, Squires L, Adler L. Long-term safety and effectiveness of lisdexamfetamine dimesylate in adults with attention-deficit/hyperactivity disorder. CNS Spectr. 2009;14(10):573-85.

75. Owens J, Gruber R, Brown T, Corkum P, Cortese S, O'Brien L, et al. Future research directions in sleep and ADHD: report of a consensus working group. J Atten Disord. 2013;17(7):550-64. doi:10.1177/1087054712457992.

76. Stein MA, Weiss M, Hlavaty L. ADHD treatments, sleep, and sleep problems: complex associations. Neurotherapeutics. 2012;9(3):509-17. doi:10.1007/s13311-012-0130-0.

77. Cortese S, Faraone SV, Konofal E, Lecendreux M. Sleep in children with attention-deficit/hyperactivity disorder: meta-analysis of subjective and objective studies. J Am Acad Child Adolesc Psychiatry. 2009;48(9):894-908. doi:10.1097/CHI. 0b013e3181ac09c9.

78. Kooij JJ, Middelkoop HA, van Gils K, Buitelaar JK. The effect of stimulants on nocturnal motor activity and sleep quality in adults with ADHD: an open-label case-control study. J Clin Psychiatry. 2001;62(12):952-6.

79. Adler LA, Goodman D, Weisler R, Hamdani M, Roth T. Effect of lisdexamfetamine dimesylate on sleep in adults with attentiondeficit/hyperactivity disorder. Behav Brain Funct. 2009;5:34. doi:10.1186/1744-9081-5-34.

80. Surman CB, Roth T. Impact of stimulant pharmacotherapy on sleep quality: post hoc analyses of 2 large, double-blind, randomized, placebo-controlled trials. J Clin Psychiatry. 2011;72(7):903-8. doi:10.4088/JCP.11m06838.

81. Giblin JM, Strobel AL. Effect of lisdexamfetamine dimesylate on sleep in children with ADHD. J Atten Disord. 2011;15(6):491-8. doi:10.1177/1087054710371195.

82. Jasinski DR, Krishnan S. Abuse liability and safety of oral lisdexamfetamine dimesylate in individuals with a history of stimulant abuse. J Psychopharmacol. 2009;23(4):419-27. doi:10. 1177/0269881109103113.

83. Kaland ME, Klein-Schwartz W. Comparison of lisdexamfetamine and dextroamphetamine exposures reported to US poison centers. Clinical Toxicol (Philadelphia, Pa). 2015;53(5):477-85. doi:10.3109/15563650.2015.1027903.

84. Hechtman L. Effects of treatment on the overall functioning of children with ADHD. Can Child Adolesc Psychiatr Rev. 2005;14(Suppl. 1):10-5.

85. Jasinski DR, Krishnan S. Lisdexamfetamine dimesylate (NRP104 / LDX) clinical abuse liability studies. 2006. http://library. corporate-ir.net/library/17/179/179878/items/203251/presentation 62606.pdf. Accessed 23 Oct 2013.

86. Rowley HL, Kulkarni R, Gosden J, Brammer R, Hackett D, Heal DJ. Lisdexamfetamine and immediate release $d$-amfetaminedifferences in pharmacokinetic/pharmacodynamic relationships revealed by striatal microdialysis in freely-moving rats with simultaneous determination of plasma drug concentrations and locomotor activity. Neuropharmacology. 2012;63(6):1064-74. doi:10.1016/j.neuropharm.2012.07.008.

87. Krishnan S, Pennick M, Stark JG. Metabolism, distribution and elimination of lisdexamfetamine dimesylate: open-label, singlecentre, phase I study in healthy adult volunteers. Clin Drug Investig. 2008;28(12):745-55. doi:10.2165/0044011-20082812000002.

88. Shire Pharmaceuticals. A phase I, open-label, randomized, four period crossover drug interaction study to evaluate the pharmacokinetic profiles of Vyvanase $\mathrm{TM}^{\mathrm{TM}}$ and Adderall XR when each is administered alone and in combination with the proton pump inhibitor Prilosec $\mathrm{OTC}^{\mathrm{TM}}$ in healthy adult volunteers. In: ClinicalTrials.gov [Internet]. Bethesda (MD): National Library of Medicine (US). 2000-[cited 31 October 2013]. http:// clinicaltrials.gov/show/NCT00746733 NLM Identifier: NCT00746733. Accessed 31 Oct 2013. 